\title{
Rajiv Shah: Handbook of foot and ankle orthopedics
}

\author{
THIEME, Stuttgart, New York, Delhi, Rio, 2016, paperback, 320 pp, 325 ill, \\ 59,99 €, ISBN: 978-93-85062-23-0
}

\author{
Alain G. Graftiaux ${ }^{1} \cdot$ Pierre Kehr $^{1}$
}

Received: 15 January 2017/Accepted: 17 January 2017/Published online: 2 February 2017

(C) Springer-Verlag France 2017

Here is a useful little book for the surgeons who are interested in the surgery of the foot and of ankle. This book makes the tower of the surgery of the foot by describing tested techniques which have the favor of the author.

The first part describes the clinical examination and the complementary examinations, the local anesthesias, the installation and the instrumentation necessary, but also the regulation of orthèses.

This book takes again the experiment of the author with many algorithms, tips and tricks for various pathologies approached, such as insult, malunion, deformities, diabetic foot, planar pains, infections, lesions of the Achilles' tendon.
Other chapters insist on the importance of the cutaneous cover, or the position of the arthrodèses.

Many illustrations are very useful, but it is not about a book of surgical techniques and it will be necessary that the reader will seek in another handbook the detailed techniques.

The interest of the book is elsewhere, gathering on 300 pages a philosophy of the assumption of responsibility of pathologies of ankle and the foot.

Compliance with ethical standards

Conflict of interest None.

Pierre Kehr

pierre.kehr@gmail.com

1 Strasbourg, France 